\title{
O POLICIAMENTO COMUNITÁRIO COMO UMA PRÁTICA SOCIAL E O GERENCIALISMO NA SEGURANÇA PÚBLICA: ANÁLISES DE UMA UNIDADE OPERACIONAL DA POLÍCIA MILITAR ${ }^{12}$
}

\author{
Daniel Victor de Sousa Ferreira ${ }^{3}$ \\ Jacquelaine Florindo Borges ${ }^{4}$
}

http://dx.doi.org/10.1590/1413-2311.298.105005

\section{RESUMO}

A partir da perspectiva da estratégia como uma prática social e de uma orientação etnometodológica, a questão de pesquisa deste artigo é: como ocorrem as micro práticas de policiamento conduzidas por membros de uma Unidade Operacional da Polícia Militar, em um contexto em que predominam macro práticas da Nova Gestão Pública e Polícia Comunitária? $\mathrm{Na}$ pesquisa de campo, foram utilizadas técnicas de pesquisa documental, entrevistas com policiais e observação participante, com notas em caderno de campo de reuniões comunitárias e do atendimento aos moradores por telefone e por aplicativo de mensagens virtuais e emergências policiais. Os resultados mostram que as micro práticas de policiamento comunitário estão imersas em uma tensão entre uma abordagem participativa do policiamento comunitário e macro práticas que privilegiam os instrumentos da administração pública gerencial. Esta pesquisa mostra que a perspectiva da estratégia como uma prática social oferece alternativas para lidar com essas tensões.

\footnotetext{
${ }^{1}$ Recebido em 30/6/2020, aceito em 13/11/2020.

${ }^{2}$ Nós agradecemos ao Centro de Pesquisa e Pós-Graduação da Academia da Polícia Militar de Minas Gerais, que apoiou e autorizou a realização da pesquisa.

3 Universidade Federal de Uberlândia. Faculdade de Gestão e Negócios - Uberlândia, MG (Brasil); http://orcid.org/0000-0002-4663-2009; thunder.danvic@ hotmail.com.

4 Universidade Federal de Uberlândia - Faculdade de Gestão e Negócios - Uberlândia, MG (Brasil); https://orcid.org/0000-0001-8550-8329; jacborges@ufu.br.
}

(c) (1) @ REAd | Porto Alegre - Vol. 26 - N. 3 - Setembro / Dezembro 2020 - p. 642-672. 
Palavras-chave: Estratégia-como-prática. Segurança pública. Polícia comunitária.

\section{COMMUNITY POLICING AS A SOCIAL PRACTICE AND MANAGERIALISM IN PUBLIC SAFETY: ANALYSIS OF AN OPERATIONAL UNIT OF THE MILITARY POLICE}

From the perspective of strategy as a social practice and an ethnomethodological orientation, the research question of this article is: how do micro policing practices conducted by members of an Operational Unit of the Military Police occur in a context where macro practices of the New Public Management and Community Police predominate? In the field research, documentary research techniques, interviews with police officers and participant observation were used, with notes of community meetings, assistance to residents by telephone and messaging applications, and police emergencies. The results show that micro community policing practices are immersed in a tension between a participatory approach to community policing and macro practices that favor the instruments of managerial public administration. This research shows that the perspective of strategy as a social practice offers alternatives to deal with these tensions.

Keywords: Strategy-as-practice. Public security. Community police.

\section{LA VIGILANCIA POLICIAL COMUNITARIA COMO UNA PRÁTICA SOCIAL Y EL GERENCIALISMO EM LA SEGURIDAD PÚBLICA: ANÁLISIS DE UNA UNIDAD OPERACIONAL DE LA POLICÍA MILITAR}

A partir de la perspectiva de la estrategia como una práctica social y de una orientación etno metodológica, la pregunta de pesquisa de este artículo es ¿cómo ocurren las micro prácticas de vigilancia que son conducidas por miembros de una Unidad Operacional de la Policía Militar en un contexto en que predominan macro prácticas de la Nueva Gestión Pública y Policía Comunitaria? En la pesquisa de campo, se utilizaron técnicas de investigación documental, entrevistas a policías y la observación participativa, por medio de notas en el cuaderno de campo de reuniones comunitarias y de atención a las personas que viven en la región por teléfono y por aplicativo de mensajes virtuales y emergencias policiales. Los resultados muestran que las micro prácticas de vigilancia policial comunitaria están inmersas en una tensión entre un enfoque participativo de la vigilancia policial comunitaria y macro prácticas que privilegian los instrumentos de la administración pública gerencial. Esta investigación muestra que la (c) (1) $\Theta$ REAd | Porto Alegre - Vol. 26 - N. ${ }^{\circ} 3$ - Setembro / Dezembro 2020 - p. 642-672. 
perspectiva de la estrategia como una práctica social ofrece alternativas para lidiar con esas tensiones.

Palabras clave: Estrategia-como-práctica. Seguridad pública. Policía comunitaria.

\section{INTRODUÇÃO}

A intenção era construir um senso de comunidade, que a polícia conversasse com as pessoas, as conhecesse, construísse a cultura coletivamente e mudasse a imagem do policial de "guerreiro" para "guardião". (BBC NEWS

Esta pesquisa se insere no campo das contradições entre os modelos de gestão pública praticados desde os anos 1980 e 1990 (PECI; PIERANTI; RODRIGUES, 2008), que Paula (2005) caracterizou como "administração pública gerencial” e "administração pública societal”. No campo da segurança pública, no Brasil, práticas de Polícia Comunitária passaram a buscar o estreitamento das interações entre o policial militar e o público civil. A ideia de Polícia Comunitária, presente em todos os estados brasileiros e largamente aceita pelas instituições de segurança pública em democracias ao redor do mundo (FERRAGI, 2011; FRÜHLING, 2007; TASCA; ENSSLIN; ENSSLIN, 2012), representa o lado progressista e avançado do policiamento (SKOLNICK; BAYLEY, 2006).

Porém, as pressões sociais por redução da violência e maior qualidade nos serviços públicos de segurança (VIEIRA; PROTÁSIO, 2011), também levaram as instituições de segurança pública a adotarem um novo paradigma de gestão, a New Public Management, ou, Nova Gestão Pública (NGP), com ênfase no planejamento estratégico e em ferramentas estatísticas e de análise de desempenho e alcance de resultados. Portanto, a prática policial passa a ser orientada pela natureza econômico-financeira e institucional-administrativa da NGP (PAULA, 2005) - Administração pública gerencial, e pela natureza sócio-política da Polícia Comunitária, que se insere em um modelo de Administração pública societal.

Tanto a NGP quanto a Polícia Comunitária foram adotadas pela Polícia Militar de Minas Gerais (PMMG). A questão de pesquisa deste artigo é como ocorrem as micro práticas de policiamento conduzidas por membros de uma Unidade Operacional da Polícia Militar, em um contexto em que predominam macro práticas da NGP e Polícia Comunitária? O objetivo da pesquisa é analisar como ocorrem as micro práticas de Polícia Comunitária conduzidas por 
membros de uma Unidade Operacional da Polícia Militar de Minas Gerais, considerando que práticas micro-macro são orientadas por diferentes propostas relacionais.

A pesquisa está fundamentada nos estudos sobre Polícia Comunitária e Nova Gestão Pública, e na concepção de micro e macro práticas dos estudos da estratégia como uma prática social: estratégia-como-prática (strategy-as-practice - SAP), a qual enfatiza que as práticas cotidianas de sujeitos imersos em contextos macro e micro são caracterizadas por uma tensão relacional (WILSON; JARZABKOWSKI, 2004). A partir de uma orientação etnometodológica (GARFINKEL, 1967), foram utilizadas para a realização da pesquisa de campo as técnicas de pesquisa documental, entrevistas e observação participante com notas do caderno de campo. As práticas do público pesquisado, composto por policiais do $17^{\circ}$ Batalhão da Polícia Militar $\left(17^{\circ}\right.$ BPM), em Minas Gerais, que realizam o policiamento comunitário, são contextualizadas com as propostas/normas federais e estaduais (macro práticas).

\section{POLÍCIA COMUNITÁRIA E GERENCIALISMO NAS PRÁTICAS POLICIAIS}

A Polícia Comunitária é uma estratégia de segurança pública que coloca em evidência a parceria entre a população/o público e a polícia. O Quadro 1 sintetiza os pressupostos da Polícia Comunitária e os pressupostos da Polícia Tradicional. Os pressupostos da Polícia Comunitária estão presentes em todos os Estados brasileiros (TASCA et al., 2012); também em países da América Latina (FRÜHLING, 2007) e nas democracias ao redor do mundo (SKOLNICK; BAYLEY, 2006). O entendimento comum é que a sociedade civil e suas diversas instituições devem participar diretamente na melhoria dos serviços públicos de segurança.

Quadro 1 - Polícia Tradicional versus Polícia Comunitária

\begin{tabular}{|l|l|l|}
\hline $\begin{array}{l}\text { Norteadores das } \\
\text { práticas policiais }\end{array}$ & \multicolumn{1}{|c|}{$\begin{array}{c}\text { Pressupostos das práticas de } \\
\text { Polícia Tradicional }\end{array}$} & \multicolumn{1}{c|}{$\begin{array}{c}\text { Pressupostos das práticas de } \\
\text { Polícia Comunitária }\end{array}$} \\
$\begin{array}{l}\text { Objetivos da } \\
\text { prática policial } \\
\text { comunitária }\end{array}$ & $\begin{array}{l}\text { Relacionamento distante: policial } \\
\text { combatente, temido e inimigo do crime. } \\
\text { Sociedade passiva e não responsável. } \\
\text { Foco no incidente criminal }\end{array}$ & $\begin{array}{l}\text { Ser conhecido e próximo da comunidade } \\
\text { local. Sociedade ativa e corresponsável. } \\
\text { Foco nos problemas da comunidade e no } \\
\text { medo do crime }\end{array}$ \\
\hline $\begin{array}{l}\text { Gestão do } \\
\text { policiamento } \\
\text { comunitário }\end{array}$ & $\begin{array}{l}\text { Centralizada e não participativa, com } \\
\text { foco no orçamento e no efetivo }\end{array}$ & $\begin{array}{l}\text { Descentralizada e participativa, com foco em } \\
\text { programas educativos, preventivos e de } \\
\text { relacionamento comunitário }\end{array}$ \\
\hline $\begin{array}{l}\text { Resultados } \\
\text { esperados da } \\
\text { prática policial } \\
\text { comunitária }\end{array}$ & $\begin{array}{l}\text { Alta capacidade de combate e } \\
\text { enfrentamento do crime via punição. } \\
\text { Consequentemente, infrator } \\
\text { amedrontado e baixos índices criminais }\end{array}$ & $\begin{array}{l}\text { Forte relacionamento com a comunidade, } \\
\text { conquistando o respeito e o apoio de todos. } \\
\text { Consequentemente, maior sensação de } \\
\text { segurança e qualidade de vida, com a } \\
\text { ausência do medo do crime e da desordem }\end{array}$ \\
\hline
\end{tabular}

Fonte: elaborado a partir de Rosenbaum (2012), Skolnick e Bayley (2006) e Trojanowicz e Bucqueroux (1994). 
A Polícia Comunitária implica uma mudança cultural, tanto dos policiais quanto do público para o qual se destinam os serviços de segurança pública. Com a mudança políticocultural promovida nos países democráticos, os pressupostos tradicionais de policiamento sofreram fortes críticas, fazendo com que se repensasse o papel da polícia (ROSENBAUM, 2012). O modelo tradicional de policiamento não era suficiente para lidar com os problemas de segurança pública (SKOLNICK; BAYLEY, 2006). As estratégias de policiamento foram reformuladas visando a aproximação entre polícia e sociedade, para que juntas se tornassem coprodutoras da prevenção do crime, da sensação de segurança e da qualidade de vida.

Os valores promovidos pelo policiamento comunitário são considerados adequados ao contexto brasileiro pós-Constituição de 1988 por serem intrínsecos à modernização da polícia. Entretanto, Batitucci et al. (2016) apontam uma ambivalência clara: a elite da PMMG considera tais valores como uma forma de ganhar legitimação. Ao mesmo tempo, tais valores são traduzidos pelo restante dos policiais de modo desvirtuado: "na prática, os valores têm papel apenas cerimonial" (BATITUCCI et al., 2016, p. 111).

Ao estudarem o caso brasileiro, Batitucci et al. (2016) mostram certo ceticismo com relação à capacidade da Polícia Militar de transformar a organização, assim como de promover nova cultura. Esse ceticismo está baseado no pressuposto de que a produção de novas práticas de policiamento ocorrerá atendo-se a novos documentos normalizadores, por meio de diretrizes e instruções documentais do comando-geral, formado por um conjunto de gestores policiais que, em média, possui pouca ou nenhuma experiência operacional. Os autores advogam que esses documentos seriam mais "mito e cerimônia" do que processo real de mudança (BATITUCCI et al., 2016, p. 89).

Em um estudo de caso das principais iniciativas da PMMG em Belo Horizonte que objetivavam a proximidade entre a Polícia Militar e a população, como as Bases Comunitárias, o Grupo Especializado de Policiamento em Áreas de Risco (Gepar) e a Rede de Vizinhos Protegidos, Batitucci et al. (2016) avaliaram a percepção dos policiais de acordo com o grau de adesão e a viabilidade em relação aos programas. No estudo, os autores assumiram duas dimensões: normativa, consultaram os documentos oficiais publicados; e, cultural, consideraram a lacuna existente entre a concepção das inovações, tal como pensada pela elite organizacional, e as subculturas dos oficiais de nível médio e atuantes na ponta.Esse estudo concluiu que a organização policial parece gastar muitos recursos e energia na difusão da filosofia de policiamento comunitário, especialmente nos documentos oficiais e para os oficiais; porém, parece não gastar o mesmo para prover reais incentivos aos gestores do nível médio 
(comandantes de batalhão e companhia) para que implementem efetivamente este modelo, conferindo-lhes habilidades e recursos para levarem o projeto adiante.

Apesar da dificuldade das polícias brasileiras em implantar o policiamento comunitário, é uma tendência presente em todo o mundo. O "policiamento comunitário cresceu a partir da concepção de que a polícia poderia responder de modo sensível e apropriado aos cidadãos e às comunidades" (SKOLNICK; BAYLEY, 2006, p. 57). Então, para lidar com os anseios sociais (múltiplos propósitos) por meio da participação social e da democracia, a polícia precisava se aproximar dos mais diversos grupos sociais, compreendendo suas mobilizações e reconhecendo suas limitações. Por consequente, era necessário que as políticas públicas de segurança fossem desdobradas territorialmente pelos municípios, permitindo que o desdobramento continuasse até às comunidades locais, numa gestão descentralizada.

Entretanto, essas mudanças na relação polícia e sociedade têm ocorrido também em meio a uma dicotomia na gestão da segurança pública: por um lado, a denominada New Public Management, ou, Nova Gestão Pública (NGP), com ênfase na quantificação, com o uso de índices auferidos cientificamente, da eficiência policial e do serviço prestado (VIEIRA; PROTÁSIO, 2011); e, por outro lado, os pressupostos da Polícia Comunitária, que pensa a gestão da segurança pública a partir não apenas da eficiência dos serviços prestados, mas de uma ampliação do diálogo com a sociedade, ouvindo e servindo as comunidades locais em suas mais diversas e variadas solicitações de segurança (ROSENBAUM, 2012; SKOLNICK; BAYLEY, 2006; TROJANOWICZ; BUCQUEROUX, 1994).

Conforme ocorre em outros estados do Brasil, a gestão pública mineira tem sido reformulada pela NGP, com o uso de conceitos e ferramentas do gerencialismo. No início dos anos 2000, a administração da Polícia Militar de Minas Gerais foi subordinada ao governo do Estado, por meio da SEDS (Secretaria de Estado de Defesa Social), que passou a ser orientada por planejamentos estratégicos previamente acordados (MINAS GERAIS [MG], 2007; POLÍCIA MILITAR DE MINAS GERAIS [PMMG], 2010; VIEIRA; PROTÁSIO, 2011). Bresser-Pereira (1998, 2002), Hood (1991) e Nikos (2001) afirmam que a NGP teria nascido como uma resposta do Estado frente aos anseios sociais por melhoria dos serviços públicos de forma geral, com a devida prestação de contas (resultados) de um Estado excessivamente burocratizado e historicamente ineficiente.

Diferentemente da descentralização das decisões e da valorização da percepção do público quanto ao serviço prestado, estimulada pela Polícia Comunitária, o gerencialismo promovido pela NGP valoriza o uso de ferramentas que garantem o controle e a eficiência da aplicação de seus recursos, auferidos numericamente. Enquanto essas ferramentas, que se (c) $\stackrel{(1) \Theta}{\Theta}$ REAd | Porto Alegre - Vol. 26 - N. 3 - Setembro / Dezembro 2020 - p. 642-672. 
afastam do sujeito e valorizam os problemas generalizantes apontados pela polícia, ganham mais notoriedade com a NGP, os pressupostos da Polícia Comunitária valorizam os problemas locais, apontados pelas próprias comunidades.

Na América latina, a reforma das práticas policias sob a égide da Polícia Comunitária está relacionada, dentre outros fatores, pelo processo de democratização ocorrido nos anos 1980 e 1990 (FRÜHLING, 2007). A ascensão da NGP (FONSECA; PEREIRA; GONÇALVES, 2015; PECI; PIERANTI; RODRIGUES, 2008) parece ser explicada "no âmbito do movimento internacional pela reforma do Estado" (PAULA, 2005, p. 65), nos anos 1980 e 1990, e, também, pela influência e simetria entre a Terceira Via, uma governança progressista (progressive governance) e o neoliberalismo; ou pelo que Hood (1991) chamou de megatendências da administração: redução dos gastos públicos, privatizações e quase-privatizações, uso da automação e tecnologia da informação na prestação dos serviços públicos, e uma agenda direcionada ao ambiente internacional e cooperação entre governos.

A implantação da Polícia Comunitária no Brasil tem sido influenciada por práticas de Política Comunitária de diferentes países da América do Norte e da Europa ocidental, nas décadas de 1970 e 1980 (FERRAGI, 2011; FRÜHLING, 2007; TASCA ET AL., 2012). A partir de uma visita técnica feita ao Estado de Nova York, USA, no final dos anos de 1990, a PMMG buscou melhorar a capacidade institucional de resposta à sociedade (VIEIRA; PROTÁSIO, 2011). Orientada por um modelo gerencialista, a PMMG passou a utilizar, já no final dos anos 1990 e início dos anos 2000, relatórios compostos por índices cientificamente auferidos.

Em meados de 2004, houve um crescente esforço da PMMG para a "criação de indicadores" e de uma estrutura administrativa voltada para "os objetivos e resultados da atividade-fim" (VIEIRA; PROTÁSIO, 2011:208). Em 2005, com o "Controle Científico da Polícia", foi estabelecida a "cientificidade das análises da eficiência dos serviços da PMMG à sociedade" (PMMG, 2010:10) visando uma "reversão do quadro de sucessivos aumentos do número de homicídios e o restabelecimento da credibilidade social do serviço policial”, mediante o entendimento que o quadro de criminalidade exigia "uma relação mais objetiva e imparcial entre avaliadores e avaliados" (VIEIRA; PROTÁSIO, 2011, p. 210).

A NGP representava uma transformação do modelo de administração burocrática para um modelo inspirado na gestão de negócios do setor privado; a gestão pública passou a valorizar então a produtividade, o desempenho, a lucratividade, a competitividade e a qualidade, com o uso de técnicas e métodos relacionados ao desempenho e à avaliação (NIKOS, 2001). Hood (1991) explica (e questiona) que o motivo de tamanha aceitação, persuasão e proliferação da 
NGP no país, deve-se ao fato que a NGP tornou-se uma das tendências internacionais mais marcantes na administração pública, na década de 1980, ao redor do mundo.

\section{A PROPOSTA RELACIONAL MICRO-MACRO NA ESTRATÉGIA VISTA COMO PRÁTICA SOCIAL}

Dos anos 1980 até início dos anos 2000 predominou uma concepção da estratégia largamente baseada na tradição macroeconômica, com ênfase no comportamento das empresas e dos mercados, com análises e diagnósticos que reduzem a estratégia a algumas variáveis com pouca evidência da ação humana (JARZABKOWSKI; BALOGUN; SEIDL, 2007). Historicamente, esta perspectiva também contribuiu para a centralidade e a posição elitista do estrategista, símbolo da modernidade (WHITTINGTON, 2004; WILSON; JARZABKOWSKI, 2004). Disso decorrem as críticas, desde o final dos anos 1990, à predominância de pressupostos modernistas e positivistas (WHITTINGTON, 2004), ao uso de metas e objetivos de longo prazo e de modelos analíticos e prescritivos fundamentados em uma abordagem economicista (JARZABKOWSKI ET AL., 2007; WILSON; JARZABKOWSKI, 2004).

Para pensar a estratégia após o modernismo, Whittington (2004) defende a pesquisa da pluralidade das práticas. Nos estudos da estratégia como uma prática social, a formulação e a implementação da estratégia são processos coexistentes e interdependentes (WILSON; JARZABKOWSKI, 2004). A estratégia deixa de ser analisada como um substantivo ou uma propriedade das organizações para ser pensada como um verbo: strategizing; a estratégia baseada nas práticas privilegia as pessoas em ação, o que elas estão fazendo cotidianamente (JARZABKOWSKI, 2004; JARZABKOWSKI ET AL., 2007; JOHNSON; LANGLEY; MELIN; WHITTINGTON, 2007; WHITTINGTON, 2004), e tais práticas devem ser compreendidas em seu contexto social mais amplo (JARZABKOWSKI ET AL., 2007; WHITTINGTON, 2007).

Do ponto de vista epistemológico e metodológico, o pesquisador que busca estudar as práticas estratégicas deve, primeiramente, reconhecer que essas práticas micro e macro existem em uma tensão relacional, essas práticas influenciam e são influenciadas mutuamente, coexistem e interagem por meio de diversos fatores intermediários (WILSON; JARZABKOWSKI, 2004). De forma geral, na macro análise, destacam-se as instituições sociais, econômicas e políticas; na micro análise, destacam-se os discursos, as práticas e os instrumentos. As práticas ocorrem em contextos amplos, mas também em micro contextos onde 
a ação está localizada, ou seja, elas ocorrem dentro de uma interação coexistente e fluída entre os contextos micro e macro (JARZABKOWSKI, 2004; WILSON; JARZABKOWSKI, 2004).

$\mathrm{O}$ interesse de estudiosos da estratégia pelas micro práticas se deve aos resultados desapontadores obtidos no nível organizacional em decorrência da negligência dessas; e, ao entendimento do papel da responsabilidade dos gestores, que estão engajados nas micro atividades (WHITTINGTON, 2004). Porém, o foco unicamente nas micro atividades traz riscos, advertem Wilson e Jarzabkowski (2004), pois quando se ignora o contexto, os estudos das micro atividades tendem ao mero reducionismo. Para evitar esse risco, o pesquisador deve considerar os microfenômenos, traduzidos por micro ações, em seu contexto social mais amplo (JARZABKOWSKI ET AL., 2007).

$\mathrm{O}$ acontecimento de qualquer atividade estará relacionado tanto ao contexto macro quanto ao micro (WILSON; JARZABKOWSKI, 2004). Para o estudo da estratégia, essa conexão entre o nível micro e macro estão a integração e um movimento alternado entre uma visão ampla e outra mais restrita do strategizing (SEIDL; WHITTINGTON, 2014); melhor entendimento de como as práticas locais participam nas grandes configurações sociais, econômicas e políticas e como essas moldam práticas e recursos locais (NICOLINI, 2009); e maior atenção à tensão relacional entre as atividades estratégicas locais e os fenômenos sociais mais amplos, consideradas como práticas dos sujeitos e práticas dos contextos (JARZABKOWSKI ET AL., 2007; NICOLINI, 2009; SEIDL; WHITTINTON, 2014).

Em estudo sobre uma perspectiva dialética das tensões relacionais geradas no processo multinível da mudança organizacional, Panayiotou, Putnam e Kassinis (2019) concluem que a mudança não é sempre o resultado de intenções deliberadas, a mudança não acontece a despeito de consequências não pretendidas, ocorre, sim, por causa delas. É central, portanto, para essa perspectiva, uma análise das tensões e das respostas a essas: uma interface entre a vivência dos atores (identidades, experiências, valores) e as decisões baseadas em uma mentalidade de organizing e strategizing.

Uma concepção relacional da estratégia também exige uma visão das interconexões entre processo e práticas (Strategy Process and Practices - SAPP) como foco na temporalidade da estratégia, nos atores e na agência, na cognição e na emoção, na materialidade e nas ferramentas e nos instrumentos mobilizados nas práticas, nas estruturas e nos sistemas e, por fim, na linguagem e nos significados (BURGELMAN ET AL., 2018). Em estudo sobre a pesquisa qualitativa do processo de estratégia, Kouamé e Langley (2018) falam da necessidade de conectar os processos e as práticas do micro nível com os resultados no nível organizacional. Ao analisar a interseção entre o Processo de Estratégia (Strategy Process - SP) e a estratégia (ㄷ) (1) $\Theta$ REAd | Porto Alegre - Vol. 26 - N.o 3 - Setembro / Dezembro 2020 - p. 642-672. 
como prática (Strategy-as-Practice - SAP), Mirabeau, Maguire e Hardy (2018) mostram que a estratégia se manifesta em uma variedade de caminhos: pretendida, realizada, deliberada, emergente, não realizada e efêmera. Essa conclusão leva ao questionamento das tensões entre essas diferentes manifestações e, sobretudo, as tensões que caracterizam cada manifestação.

Os esforços dos pesquisadores para integrar perspectivas micro e macro continuam (ECKARDT ET AL., 2019). Jalonen, Schildt e Vaara (2018) mostram que conceitos estratégicos são ferramentas do micro nível, em um estudo sobre sensemaking estratégico, em que gestores públicos inserem o conceito de "autorresponsabilidade" em busca de legitimação de um projeto público de transformação de uma cidade. A mudança depende dos gestores alcançarem uma mudança cultural, de significado, no campo das atribuições de responsabilidade entre governo, cidadãos e empresas privadas. Além das práticas de construção dos significados, as práticas narrativas também são centrais em processos de mudança e interação multinível (DALPIAZ; DI STEFANO, 2018), pois as narrativas mostram que os significados da mudança são construídos e reconstruídos por aqueles que fazem a estratégia; e a habilidade desses para lidar com a ambiguidade e as tensões que giram em torno da familiaridade e da novidade relacionadas à mudança.

\section{PROCEDIMENTO METODOLÓGICOS}

Esta pesquisa foi fundamentada em uma perspectiva interpretativista da estratégia (RASCHE; CHIA, 2009) vista como uma prática social, a partir da qual, o público pesquisado (Quadro 2) e suas interpretações se tornam centrais. Quanto à abordagem dos dados, esta pesquisa adota uma abordagem de natureza qualitativa.

Quadro 2 - Níveis de análise: práticas macro e micro

\begin{tabular}{|c|l|}
\hline Níveis de análise & \multicolumn{1}{c|}{ Coleta de dados e Público pesquisado } \\
\hline Macro & $\begin{array}{l}\text { Pesquisa documental (leis, normas, regulamentos e notícias } \text { on-line): Governo } \\
\text { Federal, Estado de Minas Gerais e Polícia Militar de Minas Gerais. }\end{array}$ \\
\hline Micro & $\begin{array}{l}\text { Entrevistas, observação participante e notas de caderno de campo: Policiais do } 17^{\circ} \\
\text { BPM que lidam cotidianamente com as práticas de policiamento comunitário. }\end{array}$ \\
\hline
\end{tabular}

Fonte: elaborado pelos autores.

Em relação ao local da pesquisa de campo, o estudo foi realizado com a PMMG, na cidade de Uberlândia, uma das maiores cidades do Estado de Minas Gerais. Na cidade, atuam quatro Unidades de Execução Operacional da PMMG, além uma Unidade de Direção Intermediária chamada de $9^{a}$ Região da Polícia Militar ( $\left.9^{\mathrm{a}} \mathrm{RPM}\right)$, responsável por dezoito (c) $\left(\right.$ () $\left(\right.$ REAd | Porto Alegre - Vol. 26 - N. ${ }^{\circ} 3$ - Setembro / Dezembro 2020 - p. 642-672. 
municípios do norte da região do Triângulo Mineiro. A pesquisa foi desenvolvida com policiais do $17^{\circ}$ Batalhão da Polícia Militar (17 BPM). Essa unidade foi escolhida por ser a Unidade de Execução Operacional mais antiga da cidade, além de adotar práticas de policiamento comunitário reconhecidas institucionalmente.

Ainda que úteis, somente as diretrizes e os documentos institucionais não bastam para responder o que é Polícia Comunitária e como se dá essa estratégia de segurança pública da PMMG, em Uberlândia. Para o estudo das práticas cotidianas dos praticantes dessa estratégia, foi utilizada uma abordagem etnometodológica, fundamentada em Garfinkel (1967) e em Coulon (1995), também fundamentada no primeiro autor. Conforme esses autores, foi conduzida uma observação atenciosa para a análise: das práticas que evidenciam os modos de proceder dos policiais pelos quais eles interpretam constantemente a realidade social; da indicialidade ou do papel da linguagem nas práticas cotidianas de policiamento comunitário; da reflexividade que implica entender os códigos não formalizados e facilmente reconhecidos pelo senso comum que rege os comportamentos cotidianos dos policiais sobre como as coisas funcionam, e, portanto, como devem proceder; da relatabilidade que se refere às descrições feitas pelos policiais sobre as situações/práticas que produziram e experienciaram; e, da noção de membro que se refere ao domínio da linguagem comum/natural do grupo, ao acesso a um conjunto de práticas e significados do policiamento comunitário.

Para a coleta de dados foram aplicadas as seguintes técnicas: (a) pesquisa documental (RICHARDSON, 2012) em leis e regulamentos sobre a atuação policial no Brasil e em Minas Gerais; (b) entrevistas episódicas (FLICK, 2003) com duração média de 90 minutos e um total de 26 entrevistados, realizada com policiais que atuam diretamente no policiamento comunitário, incluindo os comandantes do batalhão e das companhias do $17^{\circ} \mathrm{BPM}$; e, (c) observação participante (RICHARDSON, 2012; SELLTIZ; WRIGHTSMAN; COOK, 1987) das equipes de policiamento comunitário do batalhão e das equipes gestoras, em um total de 106 horas. Para fins de confidencialidade, os entrevistados serão identificados, no presente texto, pelo código E (E1, E2, E3 e outros).

O fato de não haver policiais com atribuição específica (e exclusiva) de policiamento comunitário, dificultou a definição do público. Em tese, todos os policiais militares praticam a Polícia Comunitária, qualquer que seja sua função; entretanto, foi possível identificar, dentro do conjunto de serviços ofertados à população, aqueles programas que mais se relacionavam com a comunidade civil, cujas diretrizes possuíam objetivos especificadamente voltados para a promoção da Polícia Comunitária. Durante a coleta de dados, identificaram-se os policiais que tinham participação mais direta no policiamento comunitário. 


\subsection{PESQUISA DOCUMENTAL}

As leis e regulamentos que compuseram o corpus de pesquisa totalizaram 45 documentos e 6.787 páginas. Foram originados da PMMG (pesquisados e adquiridos no ementário da PMMG, com as palavras-chave "Polícia Comunitária", "Planos Estratégicos" e "gestão" (http://www.intranetpm.mg.gov.br), do Estado de Minas Gerais (pesquisados e adquiridos nos sites oficiais do Governo de Minas, com as palavras-chave "Polícia Comunitária" (http://www.seds.mg.gov.br/) e link direto sobre o Plano Mineiro de Desenvolvimento Integrado e Lei Orçamentária (http://www.planejamento.mg.gov.br/) e do Governo Federal (pesquisados e adquiridos nos sites oficiais do Governo Federal (http://www.justica.gov.br/; http://www.planalto.gov.br); neste caso, a palavra-chave "Polícia Comunitária" retornou 247 resultados, sendo filtrado e reduzido para 13 notícias, que mais se relacionavam com o estudo. De maneira complementar, também foram incluídas as notícias que se referiam à Polícia Comunitária divulgadas de forma oficial pelos governos Federal e Estadual, sendo totalizadas 64 notícias.

Outros documentos foram coletados no campo, no momento do contato pessoal para entrevista e realização da observação participante, nos contatos com os policiais da AGR/17 BPM e da Seção de Planejamento Operacional do $17^{\circ}$ BPM. Também foi possível capturar relatórios e estudos produzidos pelo próprio batalhão, sendo possível conhecer a rotina administrativa por meio dos seguintes documentos: cadastro geral das redes de proteção; previsão estatística-espacial para os crimes violentos; Boletins de Ocorrência Simplificados; mensagens do Painel Administrativo; Relatórios de Atividades (RAT); e, planilhas de dados estatísticos acompanhados cotidianamente pela AGR (Assessoria da Gestão para Resultados).

\subsection{ENTREVISTAS}

Indicada para pesquisas com foco no conhecimento cotidiano, a modalidade de entrevistas individuais e face-a-face (GASKELL, 2003) e entrevista episódica (FLICK, 2003) foi empregada. Um guia de entrevistas foi utilizado objetivando que os entrevistados relatassem, por meio de narrativas e argumentos, o seu ponto de vista e as suas definições das situações vividas em seu cotidiano e como aplicam as normas do policiamento comunitário. Além de episódica e individual, a entrevista realizada pode também ser caracterizada como narrativa. A narrativa privilegia a realidade experienciada pelo que conta a história, ou seja, refere-se ao que 
é real para o entrevistado, que implicam em "representações/interpretações particulares do mundo". (JOVCHELOVITCH; BAUER, 2003, p. 110).

Tabela 1 - Público pesquisado

\begin{tabular}{|c|c|c|}
\hline Programa/função & Entrevistas & $\begin{array}{c}\text { Observado } \\
\text { s }\end{array}$ \\
\hline Rede de Vizinhos Protegidos (RVP) & 9 & 9 \\
\hline Grupo Especial de Policiamento em Áreas de Risco (GEPAR) & 1 & - \\
\hline Patrulha Escolar & 5 & - \\
\hline Patrulha de Prevenção à Violência Doméstica (PPVD) & 1 & - \\
\hline Programa de Educação e Resistência às Drogas (PROERD) & 4 & 1 \\
\hline $\begin{array}{l}\text { Oficiais comandantes do Batalhão, da Companhia, do Pelotão e da pasta de } \\
\text { Polícia Comunitária }\end{array}$ & 8 & 2 \\
\hline $\begin{array}{l}\text { Assessoria de Gestão para Resultados (AGR), Seção de Planejamentos e } \\
\text { Operações (P3) e Assessoria de Comunicação Organizacional (P5) da UEOp }\end{array}$ & 3 & 2 \\
\hline
\end{tabular}

Fonte: elaborada pelos autores. * Os entrevistados participavam de mais de um programa, por isso 31 entrevistas foram realizadas e 26 policiais foram entrevistados.

O público da pesquisa selecionado para a entrevista foi composto por policiais operacionais e gestores das equipes policiais no batalhão, com mais de oito anos de carreira, e um funcionário civil recentemente admitido na PMMG. Os entrevistados trabalham: (a) na sede do $17^{\circ} \mathrm{BPM}$ ou na sede de uma das Cias PM subordinadas ao batalhão, durante o expediente administrativo; ou, (b) no serviço operacional das companhias de responsabilidade territorial do $17^{\circ}$ BPM, em um dos programas descritos na Tabela 1. Os nomes dos entrevistados foram substituídos por códigos de identificação, com o fim de preservar a confidencialidade de seus nomes verdadeiros. $\mathrm{O}$ total de 26 entrevistas renderam 1.575 minutos de áudio, os quais foram posteriormente transcritos e analisados. As entrevistas foram transcritas e analisadas como narrativas (JOVCHELOVITCH; BAUER, 2003), dessa análise emergiram os repertórios interpretativos; e, em conjunto com os demais dados coletados na pesquisa, as entrevistas também foram analisadas com o método de análise de conteúdo.

\subsection{OBSERVAÇÃO PARTICIPANTE DAS PRÁTICAS POLICIAIS, INCLUINDO NOS GRUPOS VIRTUAIS DA REDE SOCIAL}

A observação participante foi aplicada para analisar o trabalho cotidiano dos policiais militares do $17^{\circ} \mathrm{BPM}$. Essa técnica é representativa dos estudos qualitativos, sobretudo numa abordagem etnometodológica, pois valoriza o contato direto e real do pesquisador com o que (c) (1) $\Theta$ REAd | Porto Alegre - Vol. 26 - N.o 3 - Setembro / Dezembro 2020 - p. 642-672. 
está acontecendo próximo dele, realizando-se uma coleta de dados no momento em que os fenômenos analisados ocorrem, sendo possível capturar os detalhes importantes do fato observado (Richardson, 2012).

A pesquisa empírica com policiais no campo da administração é escassa e difícil de ser operacionalizada, principalmente em uma instituição militar, dado ao tempo necessário para naturalizar a presença do pesquisador junto ao grupo, para compreender e participar das interações por meio de uma necessária imersão cultural, além do risco de sua atividade e do complexo processo de autorização da pesquisa. Entretanto, foi possível reduzir tais dificuldades, pois um dos pesquisadores, sendo também policial militar, foi oficialmente autorizado pela PMMG a realizar a pesquisa, acompanhar as equipes policiais na condição de integrante delas, incluindo seu uniforme e seus equipamentos de trabalho. Essa condição para a pesquisa deve-se às características do serviço policial e para cooperar com a segurança pessoal dos envolvidos em eventuais ocorrências policiais que exigiram uma intervenção direta.

Embora o pesquisador não tivesse experiência no policiamento comunitário, nem conhecia pessoalmente as equipes pesquisadas, já trabalhava na mesma organização, e, como membro do grupo social pesquisado, o pesquisador compartilha, pessoalmente, do mesmo contexto social, com acesso direto às diversas ações e práticas policiais. Na pesquisa qualitativa, sobretudo de abordagem interpretativista, como defende Silverman (2009), considera-se o próprio pesquisar como um ato interpretativo, em que os sujeitos da pesquisa são valorizados. Com o fim de compreender o meio social, o pesquisador integra-o em um olhar participativo. A vantagem está no fato desse pesquisador já estar adaptado ao meio policial, o que torna sua participação menos invasiva; ao mesmo tempo, havia um olhar de alguém "de fora" que não tinha a experiência do policiamento comunitário.

Todas as equipes que atuavam no programa Rede de Vizinhos Protegidos (RVP) no $17^{\circ}$ BPM foram acompanhadas por meio da observação participante, o que totalizou 106 horas da seguinte forma: 5 horas com o chefe da Assessoria da Gestão para Resultados (AGR/17 BPM), na Seção de Planejamentos e Operações (P3/17 $\mathrm{BPM})$; 1 hora com um comandante de Companhia PM; 2 horas com o Proerd (Programa Educacional de Resistência às Drogas e à Violência); e, 98 horas com as equipes policiais empregadas na RVP, dentre as quais, 29 horas foram destinadas às reuniões comunitárias, dos policiais com o público civil.

No decorrer da observação, verificou-se que os policiais utilizavam o celular para se relacionarem com outros policiais e com a própria sociedade civil, inclusive no horário de folga, devido às características inerentes ao programa Rede de Vizinhos Protegidos (RVP). Por esse motivo, as mensagens trocadas no aplicativo de mensagens instantâneas Whatsapp também se 
tornaram parte do material pesquisado. O pesquisador foi então incluído em 32 grupos de Whatsapp, cujas mensagens eram, em boa parte, acompanhadas em tempo real, em conjunto com as equipes policiais. As observações foram registradas em Caderno de Campo.

\subsection{ANÁLISE DOS DADOS}

O método de análise de conteúdo (BARDIN, 1977) foi aplicado para a análise do material pesquisado. Para isso, foram identificadas a priori três categorias de análise que seriam o foco da pesquisa de campo, por terem sido identificadas como as norteadoras das micro práticas dos policiais, conforme revisão da literatura sobre Policiamento Comunitário (QUADRO 1): (a) objetivos da prática policial comunitária; (b) rotinas de gestão do policiamento comunitário; e, (c) resultados esperados da prática policial comunitária.

A análise do material pesquisado considerou também os elementos-chave da etnometodologia, citados no início dessa seção: práticas, indicialidade, reflexividade, relatabilidade e noção de membro (COULON, 1995; GARFINKEL, 1967). O modo como esses elementos caracterizam o cotidiano dos policiais que praticam o policiamento comunitário em um contexto em que eles lidam também com o policiamento tradicional (QUADRO 1). A transcrição das entrevistas e os registros do Caderno de Campo foram analisadas com o auxílio do software Atlas.ti. Esta análise das micro práticas foi contrastada com a análise das macro práticas registradas com a pesquisa documental (QUADRO 2), também auxiliada pelo software Atlas.ti.

\section{APRESENTAÇÃO DOS RESULTADOS}

\subsection{UMA REDE DE PROTEÇÃO PREVENTINA}

A Rede de Proteção Preventiva (RPP) é um programa de policiamento comunitário aplicado no $17^{\circ} \mathrm{BPM}$, o qual busca conquistar a confiança do público, numa maior proximidade entre a comunidade e o policial militar, passando este a ser uma referência local. Outro objetivo do programa é sensibilizar as pessoas a adotarem mudanças de comportamentos, principalmente com medidas de autoproteção. Para tal, estabelece-se uma rede de proteção, mobilizando os moradores de uma rua ou de uma pequena região do bairro, em prol de objetivos ligados à segurança ou a qualquer problema apontado pela própria comunidade.

(c) $\left(\right.$ () $\Theta$ REAd | Porto Alegre - Vol. 26 - N..$^{\circ} 3$ - Setembro / Dezembro 2020 - p. 642-672. 
Junto às equipes policiais da RPP, foram observadas diversas práticas: reuniões comunitárias, patrulhamentos nas células da RPP, contatos pessoais realizados pelos policiais com os moradores locais, atendimento às reclamações, críticas e solicitações dos moradores, feitas por telefone ou pelo aplicativo de mensagens virtuais (WhatsApp), bem como às emergências policiais mais complexas que exigiam o apoio de equipes policias próximas, como as perseguições a veículos, a busca de infratores, o amparo dado às vítimas de crimes violentos, o atendimento emergencial em acidentes de trânsito e outras atividades afins.

Em conformidade com os documentos internos da PMMG, o batalhão adota diretrizes prescritivas para a promoção do policiamento comunitário, entretanto, os policiais adotam, também, a criatividade e o improviso, típicos da atividade policial comunitária. Cada grupo de moradores (geralmente de um mesmo quarteirão), participantes do programa, é chamado de “célula", formadas e mantidas por meio de reuniões comunitárias.

Há, também, os contatos pessoais realizados com os moradores, fisicamente nos patrulhamentos, e, virtualmente no aplicativo de mensagens instantâneas no celular (cada “célula" possui um grupo virtual no WhatsApp com a participação dos policiais). Os moradores possuem o número do telefone celular pessoal de alguns policiais, além de terem acesso a outros números de telefones especiais. Os participantes do programa também são identificados por meio de uma placa disposta no muro das residências.

Os policiais responsáveis pela criação das células de RPP, geralmente, são também os mesmos responsáveis pela manutenção delas. Em cada uma das quatro Companhias PM, que dividem a responsabilidade territorial do Batalhão, possui uma equipe fixa, de um ou dois policiais, destinada especificadamente a esse programa. Assim, o policial conhece bem as células e empenha-se pessoalmente em atender o público em suas mais diversas solicitações, dado sua proximidade com os moradores. Esse policial é bem conhecido pelo público, torna-se referência para muitos e, até mesmo, constrói laços de amizade.

\subsection{OS OBJETIVOS DA PRÁTICA POLICIAL COMUNITÁRIA}

A observação das práticas policiais mostrou uma contradição: gerenciar a sensação de segurança, um aspecto essencialmente subjetivo, por meio do cientificismo modernista de uma gestão pautada em resultados auferidos por indicadores, de forma objetiva e centralizada. A prevenção do crime é realizada por meio da promoção de segurança em duas frentes: combatese o medo do crime em prol da sensação de segurança (de forma personalizada, próxima ao 
público civil, origem e alvo das práticas policiais), ao mesmo tempo em que se busca a redução dos índices criminais (de forma impessoal, distante da realidade cotidiana das comunidades).

Uma saída para essa contradição foi encontrada pelos próprios policiais, ao considerar a estratégia de Polícia Comunitária como sendo o bom trato do policial militar para com o público civil. Pelo senso comum, todo ato de cortesia do policial para com o público pode ser considerado como sendo Polícia Comunitária; como por exemplo: falar um bom dia, ajudar um idoso, ou até mesmo conversar com uma criança. Os defensores dessas práticas acreditam que essa proximidade leva à redução de índices criminais; os que desaprovam afirmam que é um descuido ou uma fraqueza no combate ao crime.

Embora essa visão de Polícia Comunitária esteja presente no senso comum e, portanto, seja importante para a abordagem etnometodológica (COULON, 1995; GARFINKEL, 1967), não é a visão presente na literatura sobre Polícia Comunitária. Trojanowicz e Bucqueroux (1994, p. 15-20) afirmam que o policiamento comunitário: "não é relações públicas"; "não é condescendente com o crime"; "lida com problemas reais"; "não é apenas um nome a mais para o trabalho de serviço social”; e, sobretudo, “o policiamento comunitário não é apenas um nome a mais para outras iniciativas da polícia tais como prevenção do crime, relações da polícia com a comunidade ou o policiamento através da resolução de problemas".

Conforme a etnometodologia, a interpretação e as representações daqueles que vivenciam e produzem o mundo social por meio de atos práticos contínuos, são diversas, heterogêneas e subjetivas, embora sejam passíveis de serem analisadas, por meio das interações e consequente relatabilidade das práticas (COULON, 1995; GARFINKEL, 1967). A pesquisa constatou que as micro práticas policiais se baseiam em interpretações diversas da literatura e dos documentos pesquisados (macro práticas). A Figura 1 sintetiza os objetivos das práticas policiais observadas. No nível micro, os objetivos do policiamento comunitário são múltiplos: ora aproxima-se dos pressupostos das práticas de Polícia Comunitária, com foco no medo do crime, ora dos pressupostos das práticas de Polícia Tradicional, com foco no incidente criminal. Como dito, os documentos não dizem o que, de fato, fazem os policiais, nem tampouco, o que governa suas práticas.

Na Figura 1, as práticas policiais foram dispostas em seis grupos, quanto aos seus objetivos. Esses grupos são exemplificados pelas seguintes práticas: (ponto a) reuniões comunitárias executadas pelos policiais; (ponto b) patrulhamentos ostensivos realizados, com fins preventivos, por meio do contato comunitário; (ponto c) atendimento emergencial de uma ocorrência policial, visando prevenir crimes por meio da persecução penal, da recuperação social do infrator e do auxílio à vítima; (ponto d) atendimento de uma ocorrência policial de

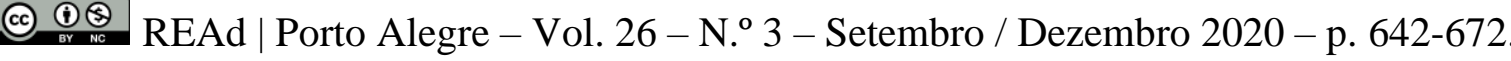


alta periculosidade e extrema complexidade, essencialmente repressivo, como quando a captura do criminoso e/ou restauração da ordem pública torna-se objetivo primal; (ponto e) patrulhamentos ostensivos em locais de grande movimento de pessoas, com fim de dissuadir infratores, sem realizar a interação comunitária; (ponto f) atendimento de uma ocorrência policial, que visa prevenir futuras infrações por meio, apenas, da autuação do infrator ou do encarceramento do criminoso.

Figura 1 - Objetivos das práticas policiais

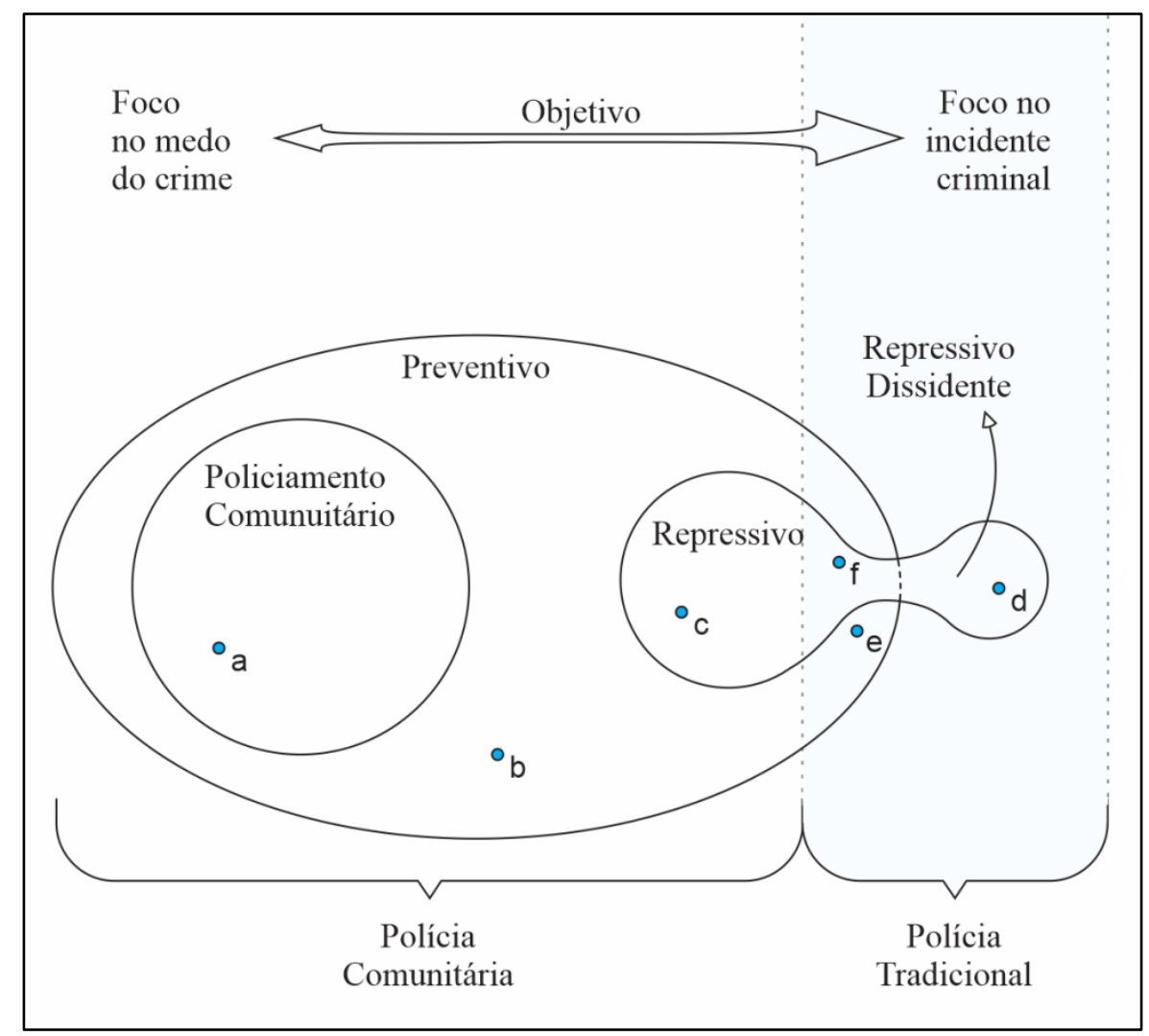

Quanto mais à direita da Figura 1, menor é o relacionamento dos policiais com o público e maior é seu interesse pelo crime violento. Essas práticas estão mais relacionadas com a gravidade das intervenções policiais, inerente ao risco que qualquer atividade policial imputa a qualquer policial militar (relacionado com o risco de vida ou o risco jurídico; os erros policiais são punidos mais severamente). De forma oposta, quanto mais à esquerda, maior é o interesse das práticas estratégicas de segurança pública com o medo do crime e a sensação de segurança, maior é o relacionamento com a comunidade, menor é o risco da atividade policial; e, maior é a necessidade da iniciativa, da criatividade e do voluntarismo dos praticantes.

Em um mesmo turno de serviço, o policial pode improvisar quaisquer práticas apontadas na Figura 1, basta que a situação, mesmo que efêmera, exija, ou, simplesmente o influencie. A 
mudança dos objetivos das práticas de policiamento, no mesmo turno, é mais frequente, e mais fácil, da esquerda para a direita, do que da direita para esquerda. Práticas à esquerda da Figura 1 necessitam do voluntarismo e da habilidade pessoal do policial; as práticas à direita são caracterizadas pelo simples cumprimento de ordens, ou procedimentos padronizados (treinados), dado o aspecto emergencial que a situação exige (risco de vida).

Quando há uma emergência grave, ou quando é afrontado por um infrator agressivo, o policial pode desenvolver ações da extrema esquerda para a extrema direita da Figura 1, em instantes. Como identificado nas entrevistas: "quem trabalha bem na polícia comunitária, trabalha em qualquer outra área da polícia, mas o contrário, não é verdadeiro” (E3); “eu acredito que tem mais policiamento repressivo [...] muitos focam no repressivo porque é mais fácil de mensurar [...] quando surgem outras demandas, o preventivo é deixado um pouco de lado" (E22). Os gestores admitem ser mais fácil avaliar e recompensar as práticas repressivas, pelas quais o desempenho policial é mais notado; como ocorrem nas notas meritórias, elogios individuais, promoção por ato de bravura e promoção post-mortem.

O risco da função policial não é apenas lembrado, mas também louvado. Morrer se torna nobre, e, lidar com a vida do público uma egrégia missão. Fragmentos do caderno de campo da pesquisa mostram que: (a) nas campanhas de valorização profissional, instituições militares do país lembram que "o militar sai de casa sem saber se volta"; (b) no final do curso de formação, no ápice da formatura, os policiais bradam o juramento de "dedicar-se inteiramente ao serviço policial militar, mesmo que com o sacrifício da própria vida"; (c) o slogan descrito logo abaixo do logotipo da PMMG afirma: "nossa profissão, sua vida"; (d) as canções e manobras militares valorizam os mesmos aspectos; e, (e) os cortejos fúnebres militares reafirmam a figura do herói e a missão de todos os policiais militares, ligada diretamente à vida, de si e de outros.

As equipes policiais de forma geral, e de maneira mais recorrente, estão geralmente orientadas por objetivos de atividades repressivas, o que influencia os policiais a valorizarem, a praticarem e a se justificarem com base nos mesmos valores típicos da Polícia Tradicional.

\subsection{A GESTÃO DA PRÁTICA POLICIAL COMUNITÁRIA}

Com base nos pressupostos da Polícia Comunitária, a PMMG vem "incentivando as comunidades a se organizarem no sentido da participação em reuniões para apresentar percepções sobre o policiamento" (VIEIRA; PROTÁSIO, 2011, p. 208). A proposta é que os cidadãos mineiros passassem a participar ativamente das políticas públicas, incluindo as de segurança, resguardados pelos anseios de cidadania e de democracia, produzindo novos relacionamentos do Estado com a sociedade. 
Como norteador das práticas policiais, analisou-se a gestão do policiamento comunitário, representada também pela rotina administrativa do batalhão, realizada pelos policiais empregados na RPP, pelos policiais gestores e seus auxiliares, que objetivava: confeccionar relatórios às instâncias superiores; manusear o banco de dados sobre os índices criminais; analisar e apresentar estudos estatísticos; e, assessorar diretamente o comando em assuntos ligados aos índices, metas e estatísticas no geral.

No nível das macro práticas, há uma preocupação da PMMG em promover as práticas de Polícia Comunitária. Os documentos e diretrizes que versam sobre Polícia Comunitária na PMMG mostram que se busca promover a participação da comunidade, para que, assim, reduzam-se as taxas de ocorrências e o medo do crime (ambos, correlacionados positivamente). Desde a década de 1990, a PMMG estimula, por meio de suas diretrizes internas, reforma de suas práticas policiais sob a égide da Polícia Comunitária, ao mesmo tempo em que tem se valorizado as técnicas e os métodos gerencialistas.

A análise das práticas estratégicas de gestão do policiamento mostrou forte influência do gerencialismo promovido pela NGP, com o emprego de metas e indicadores de desempenho, auferidos pela própria PMMG, na chamada "gestão orientada por resultados". Doutrinariamente, as práticas de policiamento comunitário são gerenciadas por meio de documentos com abordagem prescritiva e imposta pela alta direção da PMMG, visto que o termo "estratégia", na PMMG, é interpretado por uma visão positivista e funcionalista do planejamento estratégico. Conforme dados da pesquisa, no Plano Estratégico 2016-2019 da PMMG, usam-se termos/instrumentos próprios da estratégia de negócios como, por exemplo, Balanced Scorecard, Matriz SWOT, marketing e vantagem competitiva; e observou-se um esforço da PMMG em adaptar esses conceitos, já largamente utilizados no setor privado, em suas práticas de gestão policial do setor público.

A gestão do policiamento comunitário em análise, portanto, não é conduzida com base em uma perspectiva da estratégia voltada à prática. É possível que a estratégia se desvincule das imparcialidades cientificistas do modernismo, com uma visão mais direcionada à prática (WHITTINGTON, 2004), mas, não é o caso das análises realizadas na presente pesquisa. Assim como os objetivos da prática policial, o foco da gestão do policiamento comunitário também está no incidente criminal, visto ainda como prioritário, até mesmo pelas formas de premiação/recompensa. A gestão ainda é centralizada e não participativa, com foco no orçamento e no efetivo policial.

Os pressupostos da Polícia Tradicional ainda estão fortemente presentes, o que mostra desafios culturais com a implantação dos pressupostos da Polícia Comunitária, o enfrentamento 
ao afastamento entre a polícia e o público, além de mudanças na prestação de contas, por meio da descentralização e da inclusão do público civil nas práticas estratégicas. Ao situar a prática policial socialmente, conduzidas pelos pressupostos da Polícia Comunitária, a gestão das políticas públicas de segurança se torna mais próxima da comunidade local, com objetivos ligados à qualidade de vida e à sensação de segurança. Ou seja, a comunidade enquanto um conceito torna-se uma ferramenta do nível micro (JALONEN; SCHILDT; VAARA, 2018) para se pensar um policiamento distinto daquele tradicional/punitivo, o que exige também a mudança de atribuições e de responsabilidade na segurança pública. As narrativas registradas na pesquisa de campo mostram que a construção dos significados (DALPIAZ; DI STEFANO, 2018) do policiamento comunitário é influenciada não apenas pelos documentos que normatizam e preconizam essa prática, mas também pelo fato de que os policiais precisam estar preparados para agir preventivamente (policiamento comunitário) e punitivamente (situações de crimes), sempre que estão em campo.

\subsection{OS RESULTADOS ESPERADOS DA PRÁTICA POLICIAL COMUNITÁRIA}

Para a análise dos resultados esperados foi elaborada a Figura 2, construída a partir das demandas recebidas pelos diferentes níveis hierárquicos da organização e da prestação de contas. A pesquisa mostrou uma dicotomia entre os resultados práticos, presentes no atendimento cotidiano da comunidade local, visando alcançar uma sensação de segurança e os resultados normativos generalizadores, presentes nos documentos e relatórios gerenciais, produzidos tanto pelos policiais empregados na RPP quanto pelos policiais gestores.

As análises gerenciais feitas pelas seções administrativas do batalhão são realizadas em duas frentes: (a) analisam-se os relatórios confeccionados pelos policiais da atividade-fim como, por exemplo, registros dos crimes, registros das criações das células de RPP e registro das reuniões comunitárias; frente às (b) metas e indicadores criados pelo comando do Batalhão, pela PMMG e pelo Estado de Minas Gerais. Assim, a gestão do Batalhão, por meio dos números, está mais ligada às mudanças (aumento e diminuição) dos registros documentais (atividade-meio) do que às práticas policiais (atividade-fim).

Os policiais empregados na RPP também realizam atividade-meio, sendo cobrados pelo aumento/diminuição dos registros. Os policiais não são cobrados, necessariamente, pelas práticas, são cobrados pelo que os documentos consideram como resultado: os registros. $\mathrm{Na}$ prática gerencial, a avaliação quantitativa sobressai à qualitativa. Os policiais empregados na 
RPP entregam resultados diferentes para cada uma dessas atividades: a administrativa e a operacional, como as chamam.

Figura 2 - Resultado normativo versus resultado prático

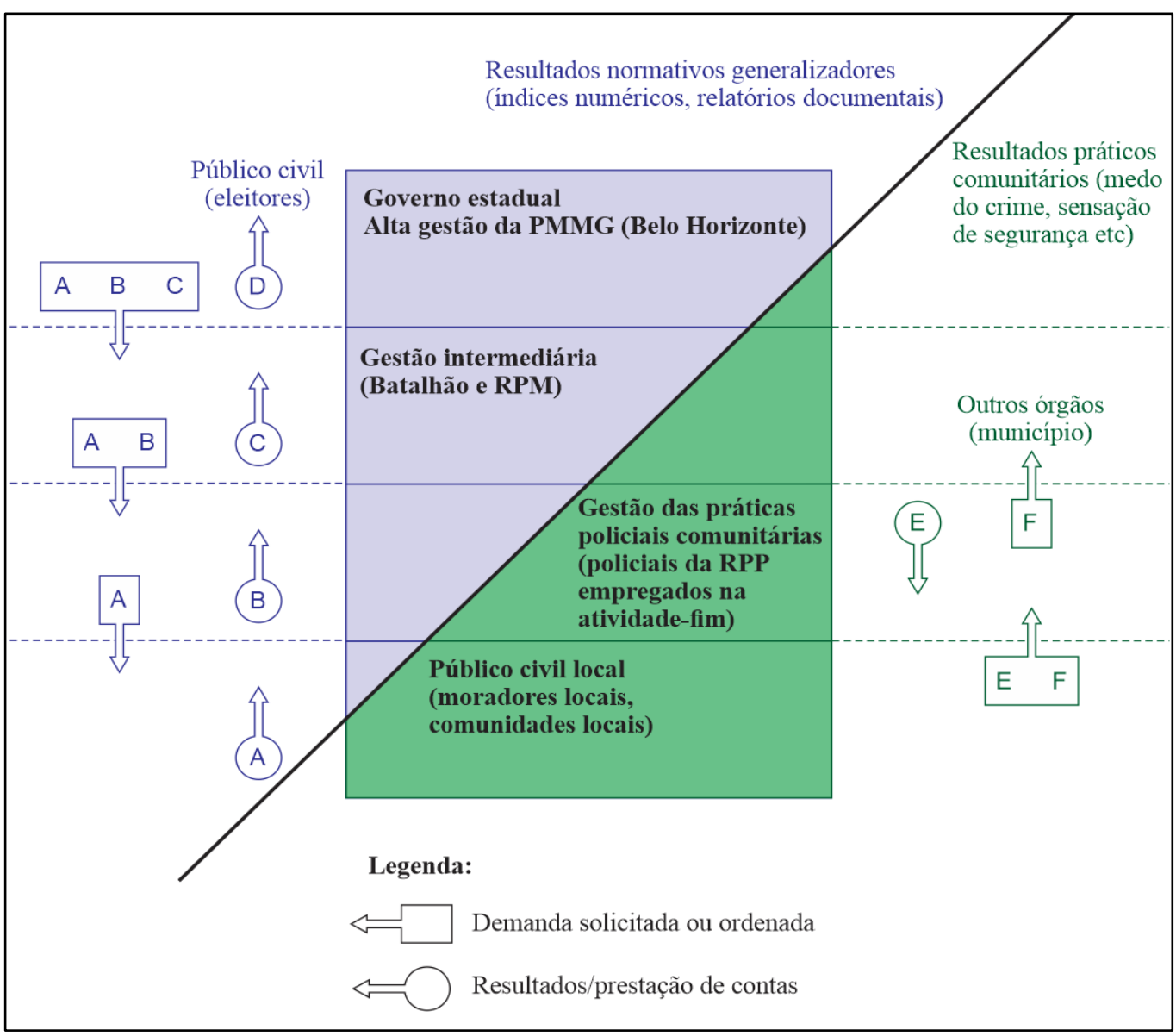

Dentro da gestão intermediária (Figura 2), as práticas de gestão do batalhão não lidam com o público civil, apenas recebe a demanda solicitada/ordenada pelo escalão administrativo superior, para o qual também entrega seus resultados normativos generalizadores (documentais). As seções administrativas do batalhão traduzem, aos policiais empregados na atividade-fim, as metas recebidas da alta gestão em Belo Horizonte. Os relatórios são produzidos, condensados, trabalhados estatisticamente e enviados para os escalões superiores como resultados. Algumas metas são consideradas difíceis ou impossíveis de serem traduzidas; para esses indicadores, os próprios policiais das seções administrativas empenham-se em acompanhar as variáveis e produzir os resultados.

Tanto os crimes quanto as reuniões comunitárias são gerenciadas pelo mesmo mecanismo: relatórios e estatísticas; ou seja, as seções administrativas do batalhão não analisam as práticas de policiamento, na atividade-fim, elas analisam as práticas de se registrar um 
relatório. A gestão, portanto, não tem o foco na atividade-fim, mas o foco nos registros burocráticos da atividade-meio, exercida de forma centralizada.

Os policiais empregados cotidianamente na atividade-fim do policiamento comunitário lidam, portanto, com dois tipos de resultados: entregam um resultado documental, com base nos relatórios e nos índices numéricos, assumindo um papel da atividade-meio ao confeccionar relatórios documentais; e, ainda, entregam um resultado prático, auferido subjetivamente em resposta a uma demanda proveniente do próprio público civil local com o qual interage de forma pessoal e constante. Essas duas maneiras de prestar contas não são coincidentes, o policiais da RPP empregados na atividade-fim, praticantes das estratégias de policiamento comunitário, devem lidar com a demanda micro, que é múltipla, local e subjetiva, bem como lidar com as decisões da alta gestão, que é generalizadora, centralizada e responsável pelo planejamento estratégico normativo do Estado e pelos resultados estatísticos entregues aos eleitores.

\section{A TENSÃO RELACIONAL MICRO-MACRO NO POLICIAMENTO COMUNITÁRIO}

A pesquisa mostrou que os repertórios do nível macro (pesquisa documental de leis, normas, regulamentos e notícias on-line do Governo Federal, do Estado de Minas Gerais e da Polícia Militar de Minas Gerais), apresentados no Quadro 3, foram ressignificados pelas interpretações de policiais militares do $17^{\circ} \mathrm{BPM}$ que lidam cotidianamente com as práticas de policiamento comunitário, conforme os repertórios que emergiram das entrevistas, da observação participante e dos registros em Caderno de Campo da pesquisa em grupos virtuais da rede social WhatsApp, apresentados no Quadro 4.

No Quadro 4, as interpretações realizadas por policiais praticantes do policiamento comunitário foram dispostas em Repertórios Interpretativos que mostram que ao atuar em diferentes regiões da cidade, os policiais estabelecem uma divisão dessa em duas regiões: (a) regiões chamadas pelos policiais como "bairros comuns" ou "bairro normais"; (b) regiões denominadas como ZQC, sigla que representa a expressão Zona Quente de Criminalidade, propriamente policial, utilizada para indicar bairros considerados como possuidores de alto índice criminal. Embora esses crimes não estivessem nos relatórios estatísticos, estabeleceu-se a crença de que existem muitos crimes acontecendo ali; "apenas não se registram os Boletins de Ocorrência, mas há crimes ali” (notas do Caderno de Campo), afirmaram alguns. Essa ideia de regiões está baseada em preconcepções compartilhadas por todos (senso comum dos 
policiais e do público civil) com consequências danosas para aquela população, para os próprios policiais e a sociedade em geral.

Quadro 3 - Repertórios Interpretativos do nível de análise macro

\begin{tabular}{|c|c|c|}
\hline Principais inte & \multicolumn{2}{|r|}{ Exemplos de material coletado } \\
\hline \multirow{6}{*}{$\begin{array}{l}\text { É preciso conduzir as } \\
\text { práticas policiais aos } \\
\text { pressupostos da Polícia } \\
\text { Comunitária ... } \\
\text { por isso é imperioso a } \\
\text { prática de policiamento } \\
\text { comunitário, conforme o } \\
\text { previsto, por todo o país ... } \\
\text { portanto, há um esforço da } \\
\text { alta gestão e dos governos } \\
\text { federal e estadual em } \\
\text { produzir documentos } \\
\text { normativos e prescritivos de } \\
\text { policiamento comunitário. }\end{array}$} & $\begin{array}{l}\text { Legislação } \\
\text { Federal }\end{array}$ & $\begin{array}{l}\text { Decreto } \mathrm{n}^{\circ} \text { 8.243/2014. Institui a Política Nacional de } \\
\text { Participação Social (PNPS) e o Sistema Nacional de } \\
\text { Participação Social (SNPS), e dá outras providências. }\end{array}$ \\
\hline & $\begin{array}{l}\text { Secretaria } \\
\text { Nacional de } \\
\text { Segurança } \\
\text { Pública }\end{array}$ & $\begin{array}{l}\text { Curso Nacional de Promotor de Polícia Comunitária (Grupo } \\
\text { de Trabalho, Portaria SENASP n }{ }^{\circ} 14 / 2006 \text { ) }\end{array}$ \\
\hline & $\begin{array}{l}\text { Legislação } \\
\text { estadual }\end{array}$ & $\begin{array}{l}\text { Decreto } n^{\circ} \text { 27081/1987. Cria o Programa de } \\
\text { Desenvolvimento Comunitário da Polícia Militar, Programa } \\
\text { Comunitário Tiradentes, e dá outras providências }\end{array}$ \\
\hline & \multirow{3}{*}{$\begin{array}{l}\text { Polícia Militar } \\
\text { de Minas } \\
\text { Gerais }\end{array}$} & $\begin{array}{l}\text { Instrução n. 3.03.11/2016-CG: Regula a implantação da } \\
\text { Rede de Proteção Preventiva nas comunidades do Estado de } \\
\text { Minas Gerais. }\end{array}$ \\
\hline & & Relatório de monitoramento e avaliação do plano estratégico \\
\hline & & Sistema de Gestão Estratégica e Plano Estratégico \\
\hline \multirow{6}{*}{$\begin{array}{l}\text { É preciso incentivar o } \\
\text { reconhecimento da sociedade } \\
\text { civil e dos policiais ... }\end{array}$} & \multirow{3}{*}{$\begin{array}{l}\text { Notícias do } \\
\text { Governo } \\
\text { Federal }\end{array}$} & MJ capacita mais de 90 mil para policiamento comunitário \\
\hline & & $\begin{array}{l}\text { Encontro nacional de polícias comunitárias discute novas } \\
\text { estratégias }\end{array}$ \\
\hline & & $\begin{array}{l}\text { Brasil e Japão compartilham experiência de policiamento } \\
\text { comunitário }\end{array}$ \\
\hline & \multirow{3}{*}{$\begin{array}{l}\text { Notícias do } \\
\text { Governo de } \\
\text { Minas Gerais }\end{array}$} & $\begin{array}{l}\text { Concurso de Polícia Comunitária premia projetos } \\
\text { vencedores }\end{array}$ \\
\hline & & Curso capacita policiais para atuarem junto à comunidade \\
\hline & & Melhores projetos de Polícia Comunitária recebem prêmios \\
\hline \multirow{3}{*}{$\begin{array}{l}\text { portanto, há um esforço em } \\
\text { divulgar e incentivar as } \\
\text { práticas de policiamento } \\
\text { comunitário. }\end{array}$} & \multirow{3}{*}{$\begin{array}{l}\text { Notícias da } \\
\text { Secretaria de } \\
\text { Estado de } \\
\text { Defesa Social } \\
\text { (MG) - Seds }\end{array}$} & $\begin{array}{l}\text { Núcleo de Ensino Integrado da Seds realiza curso de polícia } \\
\text { comunitária }\end{array}$ \\
\hline & & Seds amplia ações de Polícia Comunitária \\
\hline & & $\begin{array}{l}\text { Seds e Prefeitura de Contagem dão curso de segurança } \\
\text { pública para líderes da sociedade civil }\end{array}$ \\
\hline
\end{tabular}

A tensão relacional micro-macro provoca um dualismo na atividade-fim: por um lado, a gestão está direcionada para os resultados normativos generalizadores requeridos pelo escalão superior; e, por outro lado, um resultado prático subjetivo, ligado ao medo do crime, à sensação de segurança, aos pequenos delitos e a qualquer outra solicitação feita pelo público civil. No primeiro caso, os problemas são apontados pelo Estado e/ou pela gestão da PMMG, da RPM ou do BPM (de forma centralizada); no segundo caso, os problemas são apontados pelos civis, a quem se destinam as práticas policiais (de forma descentralizada e particular). As práticas de promoção de programas de policiamento comunitário são de responsabilidade de policiais que também atuam na repressão criminal, fortemente baseada em justificativas estatísticas. Já os objetivos e a importância da Polícia Comunitária não deveriam estar na redução do índice REAd | Porto Alegre - Vol. 26 - N. 3 - Setembro / Dezembro 2020 - p. 642-672. 
criminal (ROSENBAUM, 2012; SKOLNICK; BAYLEY, 2006; TROJANOWICZ;

BUCQUEROUX, 1994).

Quadro 4 - Repertórios Interpretativos do nível de análise micro

\begin{tabular}{|c|c|}
\hline $\begin{array}{c}\text { Os moradores evitam o relacionamento com a } \\
\text { polícia }\end{array}$ & $\begin{array}{r}\text { Os moradores iniciam um processo } \\
\text { no relacionamento com a p }\end{array}$ \\
\hline \multicolumn{2}{|c|}{$\begin{array}{l}\text { Resultados esperados das práticas de policiamento comunitário em bairros considerados pelos policiais } \\
\text { como uma ZQC }\end{array}$} \\
\hline $\begin{array}{l}\text { Porque: } \\
\text { • poucas ações repressivas contra o grande número de } \\
\text { criminosos locais, com baixo empenho de efetivo e } \\
\text { de logística; } \\
\text { • o relacionamento com a polícia é prejudicial para a } \\
\text { população local; } \\
\text { • não são feitos os registros dos crimes que ocorrem } \\
\text { na região; } \\
\text { • o medo do crime impera. } \\
\text { Portanto: } \\
\text { • não é um problema para as metas de gestão, dada à } \\
\text { inexistência de registros criminais; } \\
\text { • é foco do policiamento tradicional, dada às } \\
\text { suspeitas do local durante as persecuções criminais; } \\
\text { - dificuldades e abandono das práticas de } \\
\text { policiamento comunitário, pois são vistas como } \\
\text { riscos para o policial e para a sociedade "de bem"; } \\
\text { •cidadania: o Estado não é visto como um } \\
\text { representante dos anseios da população local; } \\
\text { • Problema de segurança pública: irresolúvel. } \\
\text { Espera-se: índices criminais nulos; alto medo do } \\
\text { crime; } \\
\text { FRACASSO das práticas de policiamento } \\
\text { comunitário. }\end{array}$ & $\begin{array}{l}\text { Porque: } \\
\text { - mais ações repressivas contra os criminosos locais, } \\
\text { com alto empenho de logística e de efetivo; } \\
\text { • o relacionamento entre polícia e população local } \\
\text { começa a ser promovido; } \\
\text { - os registros dos crimes, que ocorrem na região, } \\
\text { começam a aumentar; } \\
\text { - o medo do crime começa a reduzir. } \\
\text { Portanto: } \\
\text { - os índices criminais tornam-se visíveis para as } \\
\text { metas de gestão, um problema a ser combatido; } \\
\text { - ainda éfoco do policiamento tradicional, dada a } \\
\text { importância de sua ação repressiva na região; } \\
\text { - ainda é difícil promover práticas de policiamento } \\
\text { comunitário, apesar dos riscos da atividade ter } \\
\text { começado a diminuir; } \\
\text { - cidadania: o Estado começa a ser visto como um } \\
\text { representante dos anseios da população local, ainda } \\
\text { de modo precário; } \\
\text { - Problema de segurança pública: resolúvel, } \\
\text { embora árduo. } \\
\text { Espera-se: aumento dos índices criminais; redução } \\
\text { do medo do crime; } \\
\text { FRACASSO das práticas de policiamento } \\
\text { comunitário. }\end{array}$ \\
\hline \multicolumn{2}{|c|}{$\begin{array}{l}\text { Resultados esperados das práticas de policiamento comunitário em bairros considerados pelos policiais } \\
\text { como bairros "comuns" ou bairros "normais" }\end{array}$} \\
\hline $\begin{array}{l}\text { Porque: } \\
\text { • não possui o medo do crime; } \\
\text { • o relacionamento com a polícia é indiferente para a } \\
\text { população local; } \\
\text { • lidam sozinhos com os poucos crimes que } \\
\text { acontecem (ou nem acontecem); } \\
\text { • são feitos poucos registros dos crimes que ocorrem } \\
\text { na região. } \\
\text { Portanto: } \\
\text { • não é um problema para as metas de gestão, dada à } \\
\text { inexistência de registros criminais; } \\
\text { - não é foco do policiamento tradicional, } \\
\text { entendimento de baixa probabilidade de ocorrência } \\
\text { de crimes; } \\
\text { - dificuldades e/ou abandono das práticas de } \\
\text { policiamento comunitário, pois são vistas pela } \\
\text { população local como desnecessárias; } \\
\text { • não é considerado um problema de cidadania, pois o } \\
\text { Estado é naturalmente visto como um representante } \\
\text { dos anseios da população local; } \\
\text { • Não é considerado um problema de segurança } \\
\text { pública }\end{array}$ & $\begin{array}{l}\text { Porque: } \\
\text { • possui um nível adequado do medo do crime, } \\
\text { geralmente produzido por determinadas ocorrências } \\
\text { de ampla divulgação; } \\
\text { • dada à configuração comunitária, em prol de } \\
\text { objetivos comuns relacionados à segurança, a } \\
\text { população local busca o relacionamento estreito com } \\
\text { a polícia; } \\
\text { - todos os crimes que ocorrem na região são } \\
\text { registrados e amplamente divulgados. } \\
\text { Portanto: } \\
\text { - é um problema para as metas de gestão, dada à } \\
\text { existência de crimes e de seus registros; } \\
\text { • possui o foco do policiamento tradicional, dada à } \\
\text { ocorrência de crimes e a tentativa de preveni-los; } \\
\text { - oportunidade para a promoção das práticas de } \\
\text { policiamento comunitário, pois são vistas pela } \\
\text { população local como necessárias; } \\
\text { - não é considerado um problema de cidadania, pois o } \\
\text { Estado é naturalmente visto como um representante } \\
\text { dos anseios da população local; } \\
\text { - Problema de segurança pública: resolúvel }\end{array}$ \\
\hline
\end{tabular}


Espera-se: índices criminais nulos; ausência do medo do crime;

- FRACASSO das práticas de policiamento comunitário.
Espera-se: controle dos índices criminais; presença mínima e adequada do medo do crime;

- SUCESSO das práticas de policiamento comunitário.

Mesmo diante das dificuldades no tratamento estatístico dos dados do policiamento comunitário, os policiais pesquisados buscam justificar a importância da promoção da RPP por meio dos números, que em tese levariam à redução dos índices criminais do batalhão. Alguns entrevistados afirmaram: "os índices são importantes porque eles dão o feedback do trabalho, mostra que o trabalho da polícia comunitária tem resultado [...] tem diminuído o crime" (E20); "o Comandante de Companhia trabalha com índice, a gente não pode pensar de maneira diferente [...] ele tem que prestar conta para o Comandante do Batalhão" (E16).

O tratamento subjetivo do medo do crime (aumento da sensação de segurança) é colocado em segundo plano quando a gestão é permeada pelos princípios gerencialistas da gestão orientada por resultados. O sentimento que essa contradição causa é o de que, apesar de haver uma aferição das taxas de ocorrências, deveriam ser utilizadas, também, outras formas de acompanhamento sistemático da correlação existente entre os índices de criminalidade e as ações do policiamento comunitário. Ao analisar os propósitos da Polícia Comunitária, Skolnick e Bayley (2006) reconhecem as possíveis dificuldades de se determinar a eficácia da participação do público como coprodutor da prevenção criminal, nas práticas do policiamento comunitário. Segundo os autores, o que parece realmente ter sido comprovado como fundamental, pelos estudos que encorajaram a avaliação da eficácia do policiamento comunitário, é a promoção de uma visão sistêmica que valoriza a reciprocidade políciacomunidade; portanto, o que se torna mais importante é o envolvimento enérgico e permanente dos policiais com os valores de prevenção, não a eficácia do policiamento na prevenção de crimes identificáveis numericamente.

Conforme Skolnick e Bayley (2006, p. 102), “devemos evitar medir as coisas erradas pois elas são mais fáceis de serem medidas - e chegar a conclusões que não foram de fato comprovadas". Por exemplo, a melhoria do relacionamento da polícia com a comunidade local, geralmente, estimula o registro de crimes. Neste caso, o aumento dos índices criminais não, necessariamente, reduz a sensação de segurança. A ausência do Estado em algumas comunidades pode até mesmo gerar a queda dos registros criminais, juntamente com a redução da qualidade de vida. Outro exemplo: o aumento das apreensões de armas de fogo e drogas, não está, necessariamente, ligado ao bom resultado prestado pela Polícia Militar ao público local; ou que realmente houve uma melhoria na persecução penal, ou apenas um verdadeiro aumento das práticas delituosas. 
A comunidade, na RPP, é a origem e o alvo das atenções do policiamento comunitário. É ao público civil que deveria ser direcionado a prestação de contas. Entretanto, numa gestão por metas, a produtividade do policial militar, como funcionário público, não está em promover essa prestação de contas à comunidade, mas, em apresentar resultados ao seu superior, por meio dos relatórios e dos números. Assim, torna-se mais produtivo o policial que promove o policiamento tradicional.

A gestão do medo por meio das estatísticas promove uma tensão na prática policial cotidiana, presente na seguinte dicotomia: (a) lidar com índices criminais documentalmente, de forma centralizada e não participativa, com foco no orçamento e no efetivo, por meio do gerencialismo; e, (b) lidar com a sensação de segurança, por meio de uma abordagem subjetiva dos praticantes da estratégia, com foco na promoção de programas preventivos e de relacionamento comunitário, cujo sucesso depende do voluntarismo, da iniciativa e da criatividade dos militares e da comunidade local.

A pesquisa mostrou que os esforços para integrar as perspectivas micro e macro (ECKARDT ET AL., 2019) continuam na prática policial comunitária. A partir da estratégia como uma prática social, que compreende as micro práticas dos policiais imersas em instituições que promovem e recompensam a partir de um modelo de gestão gerencialista, os policiais terão dificuldade em conectar os processos e as práticas do micro nível com os resultados no nível organizacional (KOUAMÉ; LANGLEY, 2018). A estratégia como prática mostra que é preciso considerar as diferentes manifestações do policiamento comunitário e aprender com elas (MIRABEAU; MAGUIRE; HARDY, 2018): pretendida, realizada, deliberada, emergente, não realizada e efêmera.

Outro caminho mostrado pela estratégia como prática é que os significados podem ser vistos como instrumentos das práticas de policiamento comunitário e também como forma de avaliar os ganhos advindos com os processos de ressignificação da relação policial-cidadão, polícia-sociedade, policial-corporação. Conforme Jalonen, Schildt e Vaara (2018) o sensemaking estratégico pode ajudar os gestores públicos na busca de legitimação de um projeto público de mudança. Obviamente, deve-se evitar que isso ocorra com propósitos de manipulação. As práticas narrativas (DALPIAZ; DI STEFANO, 2018) podem ser analisadas nas avaliações do policiamento comunitário para acompanhar a efetividade das práticas cotidianas imersas na sociedade local e orientadas macro práticas federais e estaduais.

\section{CONCLUSÕES}


Esta pesquisa mostra que as práticas estratégicas de policiamento comunitário ocorrem numa tensão relacional entre micro práticas cotidianas e macro práticas de segurança pública orientadas por questões mais amplas de reestruturação do Estado, desenvolvimento tecnológico, tendência à cooperação internacional, governança progressista, regulamentação com base em experiências vindas de outros países, pressão da sociedade e de organismos internacionais por redução da violência, dentre outros.

Estudos da estratégia como uma prática social auxiliaram a análise de micro práticas de policiamento comunitário e mostrou que essas transitam entre os paradigmas preventivo e repressivo, e, entre os pressupostos da Polícia Comunitária e da Polícia Tradicional. Apesar das macro práticas federais e estaduais estarem em direção aos pressupostos da Polícia Comunitária, os pressupostos da Polícia Tradicional ainda são importantes orientadores das micro práticas. O foco da prática policial ainda se sustenta em cumprimento de metas, sistema de recompensas e premiação, realização de treinamentos e estrutura organizacional que privilegiam as práticas da Polícia Tradicional e a ação repressiva.

A pluralidade dos objetivos do policiamento é um fato: o policiamento repressivo para lidar com o crime e o policiamento comunitário para garantir a segurança juntamente com a sociedade. Os estudos mostram que esses policiamentos são complementares, mas como praticá-los baseados na complementaridade se exigem lógicas de ação distintas e mentalidades distintas? Outra questão são os limites de análises quantitativas para se avaliar os resultados da gestão da sensação de segurança vis a vis o medo da violência, elementos da subjetividade. Tal prática provoca frustração nos praticantes que observam vantagens do policiamento comunitário que nem sempre podem ser retratadas em números.

A pesquisa mostra, portanto, que uma mudança cultural na Polícia Militar é necessária, embora insuficiente, para as práticas de policiamento comunitário. Ela é necessária, pois é preciso ressignificar a relação polícia-sociedade. As práticas de policiamento comunitário não podem avançar enquanto a polícia enxergar a cidade a partir de regiões em que esse policiamento não se aplica, devido às preconcepções sobre criminalidade, e o entendimento de que os benefícios do policiamento comunitário só podem ser alcançados em bairros específicos. A perspectiva da estratégia vista como uma prática social questiona também a atual ênfase no gerencialismo como solução para os problemas de segurança pública, e abre caminhos para futuras pesquisas no campo da segurança pública e do policiamento comunitário.

\section{REFERÊNCIAS}


BARDIN, L. Análise de conteúdo. Lisboa: Edições 70, 1977.

BATITUCCI, E. C.; GODINHO, L.; CASTRO, L. L.; GOMES, L. P. V. Policiamento Comunitário e Participação Social em Minas Gerais: Entre a Narrativa Oficial e a Efetividade das Reformas. In: OLIVEIRA JUNIOR, Almir de (org.). Instituições participativas no âmbito da segurança pública [pp. 55-117]. Rio de Janeiro: Ipea, 2016.

BBC NEWS BRASIL. Camden, a violenta cidade dos EUA que reformou sua polícia e reduziu a criminalidade, 13 jun. 2020. Disponível:

https://www.bbc.com/portuguese/internacional-52996070.

BRESSER-PEREIRA, L. C. Reforma do Estado para a cidadania. São Paulo: Editora 34, 1998.

BRESSER-PEREIRA, L. C. Reforma da nova gestão pública: agora na agenda da América Latina, no entanto..., Revista do Serviço Público, v. 53, n. 1, pp. 5-27, 2002.

BURGELMAN, R. A.; FLOYD, S. W.; LAAMANEN, T. MANTERE, S.; VAARA, E.; WHITTINGTON, R. Strategy process and practices: Dialogues and intersections. Strategic Management Journal, v. 39, n. 3, p. 531-558, 2018.

COULON, A. Etnometodologia. Petrópolis, RJ: Editora Vozes, 1995.

DALPIAZ, E.; DI STEFANO, G. A universe of stories: Mobilizing narrative practices during transformative change. Strategic Management Journal, v. 39, n. 3, p. 664-696, 2018.

ECKARDT, R. et al. Reflections on the micro-macro divide: Ideas from the trenches and moving forward. Strategic Organization, v. 17, n. 3, p. 385-402, 2019.

FERRAGI, C. A. O sistema Koban e a institucionalização do policiamento comunitário paulista. Revista Brasileira de Segurança Pública, v. 5, n. 8, pp. 60-77, 2011.

FLICK, U. Entrevista episódica. In: BAUER, M. W.; GASKELL, G. (orgs.). Pesquisa qualitativa com texto, imagem e som [pp. 114-136]. Petrópolis, RJ: Editora Vozes, 2003.

FONSECA, J. A.; PEREIRA, L. Z.; GONÇALVES, C. A. Retórica na construção de realidades na segurança pública: abordagens dos sistemas de Minas Gerais e São Paulo.

Revista de Administração Pública, v. 49, n. 2, pp. 395-422, 2015.

FRÜHLING, H. The Impact of International Models of Policing in Latin America: The Case of Community Policing. Police Practice and Research, v. 8, n. 2, pp. 125-144, 2007.

GARFINKEL, H. Studies in Ethnomethodology. Prentice-Hall, Inc., Englewood Cliffs, New Jersey, 1967.

HOOD, C. A Public Management for All Seasons? Public Administration, v. 69, n. 1, pp. 319, 1991.

JARZABKOWSKI, P. Strategy as Practice: Recursiveness, Adaptation, and Practices-in-Use. Organization Studies, v. 25, n. 4, pp. 529-560, 2004. 
JARZABKOWSKI, P.; BALOGUN, J.; SEIDL, D. Strategizing: the challenges of a practice perspective. Human Relations, v. 60, n. 1, pp.5-27, 2007.

JALONEN, K.; SCHILDT, H.; VAARA, E. Strategic concepts as micro-level tools in strategic sensemaking. Strategic Management Journal, v. 39, n. 10, 2018.

JOHNSON, G.; LANGLEY, A.; MELIN, L.; WHITTINGTON, R. Strategy as practice. New York: Cambridge University Press, 2007.

KOUAMÉ, S.; LANGLEY, A. relating micro processes to macro-outcomes in qualitative strategy process and practice research. Strategic Management Journal, v. 39, n. 3, p. 559$581,2018$.

MINAS GERAIS [MG]. Plano Mineiro de Desenvolvimento Integrado 2007-2023. Belo Horizonte, MG: SEPLAG, 2007.

MIRABEAU, L.; MAGUIRE, S.; HARDY, C. Brinding practice and process research to study transient manifestations of strategy. Strategic Management Journal, v. 39, n. 3 p. 582-605, 2018.

NICOLINI, D. Zooming In and Out: Studying Practices by Switching Theoretical Lenses and Trailing Connections. Organization Studies, v. 30, n. 12, pp.1391-1418, 2009.

NIKOS, M. Trends of Administrative Reform in Europe: Towards Administrative Convergence? International Public Management Review, v. 2, n 2, pp. 39-53, 2001.

PAULA, A. P. P. Por uma nova gestão pública. Rio de Janeiro: Editora FGV, 2005.

PANAYIOTOU, A.; PUTNAM, L. L.; KASSINIS, G. Generating tensions: A multilevel, process analysis of organizational change. Strategic Organization, v. 17, n. 1, p. 8-37, 2019.

PECI, A.; PIERANTI, O. P.; RODRIGUES, S. Governança e New Public Management: Convergências e Contradições no Contexto Brasileiro. Organização \& Sociedade, v. 15, n. 46, pp. 39-55, 2008.

POLÍCIA MILITAR DE MINAS GERAIS [PMMG]. Diretriz de Gestão para Resultados. Diretriz no 01/2010- CG. Organiza e disciplina o Sistema Integrado de Gestão para Resultados da PMMG. Belo Horizonte: Assessoria de Gestão para Resultados/Estado-Maior, 2010.

RASCHE, A.; CHIA, R. Researching Strategy Practices: A Genealogical Social Theory Perspective. Organization Studies, v. 30, n. 7, pp. 713-734, 2009.

RICHARDSON, R. J. Pesquisa Social. São Paulo: Editora Atlas, 2012.

ROSENBAUM, D. P. A Mudança no Papel da Polícia: Avaliando a transição para Policiamento Comunitário. In: BRODEUR, J. P. (Org.). Como reconhecer um bom policiamento [pp. 27-56]. São Paulo: Editora da Universidade de São Paulo, 2012. 
SEIDL, D.; WHITTINGTON, R. Enlarging the Strategy-as-Practice Research Agenda: Towards Taller and Flatter Ontologies. Organization Studies, v. 35, n, 10, pp. 1407-1421, 2014.

SELLTIZ, W.; WRIGHTSMAN, L.S.; COOK, S. W. Métodos de Pesquisa nas Relações Sociais [vol. 1], São Paulo: EPU, 1987.

SILVERMAN, D. Interpretação de dados qualitativos. Porto Alegre: Artmed, 2009.

SKOLNICK, J. H; BAYLEY, D. H. Policiamento Comunitário. São Paulo: Editora da Universidade de São Paulo, 2006.

TASCA, J. E.; ENSSLIN, L.; ENSSLIN, S. R. A avaliação de programas de capacitação: um estudo de caso na administração pública. Revista de Administração Pública, v. 46, n. 3, pp. 647-675, 2012.

TROJANOWICZ, R.; BUCQUEROUX, B. Policiamento Comunitário. Rio de Janeiro: Polícia Militar do Estado do Rio de Janeiro, 1994.

VIEIRA, R.; PROTÁSIO, G. Gestão para resultados na segurança pública em Minas Gerais: uma análise sobre o uso de indicadores na gestão da Polícia Militar e no Sistema de Defesa Social. Revista Brasileira de Segurança Pública, v. 5, n. 8, pp. 206-220, 2011.

WHITTINGTON, R. Estratégia após o modernismo: recuperando a prática. Revista de Administração de Empresas, v. 44, n. 4, pp. 44-53, 2004.

WHITTINGTON, R. Strategy practice and strategy process: family differences and the sociological eye. Organization Studies, v. 28, n. 10, pp.1575-1586, 2007.

WILSON, D. C.; JARZABKOWSKI, P. Thinking and acting strategically: new challenges for interrogating strategy. European Management Review, v. 1, n. 1, pp. 14-20, 2004. 